\title{
"Os Encontros de Saberes": equívocos entre índios e Estado em torno das políticas de saúde indígena na Venezuela ${ }^{1}$
}

\author{
Jose Antonio Kelly Luciani
}

Universidade Federal de Santa Catarina, Florianópolis, Brasil

E-mail:kamiyekeya@gmail.com 


\section{Resumo}

A partir de uma reunião entre representantes dos yanomamis e do sistema de saúde oficial da Venezuela, realizada em La Esmeralda (estado do Amazonas), no ano de 2004, este artigo discute alguns aspectos críticos da relação entre o Estado venezuelano e os yanomamis dentro do campo da saúde e além. O artigo tem duas partes. Na primeira delas, considero as circunstâncias históricas e ideológicas que, dentro da era do multiculturalismo, favorecem o tipo de "encontros de saberes" dos quais essa reunião foi um exemplo. Esta parte constitui um comentário crítico sobre como as noções de cultura e identidade podem atrapalhar a análise da saúde indígena ao obscurecer a existência de redes de relações - entre Estado e comunidade, entre índios e brancos - que influenciam a determinação dos perfis sanitários das comunidades. A segunda parte do ensaio segue nos temas de cultura e identidade, mas desloca o foco para iluminar outro tipo de problema. Ao promover um diálogo intercultural, a reunião (batizada como "Encontro de Saberes") foi um momento de interpretação e tradução recíproca entre índios e brancos. A análise do que cada um desses atores traduz do outro revela os equívocos que tão frequentemente caracterizam as relações entre índios e Estados nacionais. Essa análise se nutre da crítica de Roy Wagner (1981) à própria antropologia e da noção de 'equívoco controlado' discutida por Eduardo Viveiros de Castro (2004).

Palavras-chave: Saúde indígena. Etnologia indígena. Relação ÍndioEstado. Yanomami. Equívocos.
Abstract

The following paper uses the occasion of a meeting of State health officials and Yanomami representatives held in La Esmeralda in 2004 as the basis two discuss some critical aspects of the relation between Yanomami and the state, within and the beyond the realm of health. The paper is divided in two parts. In the first one, I shall consider the ideological and historical circumstances that in the multicultural era allows for the kind of "Knowledge Encounters" of which this meeting was an example. This part is a critical commentary of how common sensical notions of culture and identity can work against a thorough analysis of indigenous health, in as much as they can obscure the existence of networks of relations - between community and State, indians and non-indians - and hence downplay their influence in determining the sanitary profile of people and communities. The second part of the essay remains within the subject of culture and identity but changing focus in order to illustrate another set of problems. These meetings (baptised as they were as "Knowledge Encounters", Encuentros de Saberes in Spanish) as intercultural dialogues are moments of reciprocal interpretation and translation of Indian and non-indian actors. I will extend myself on the examination of what each party to this encounter translates of the other as a way to illuminate equivocations that so often appear in relations between Indians and the State. This analysis takes its references from Wagner's (1981) own critique of anthropological enquiry and the notion of "controlled equivocation" recently expounded by Viveiros de Castro (2004).

Keywords: Indigenous health. Amazonianist anthropology. Indian-State relations. Yanomami. Equivocations. 


\section{Introdução}

耳 m novembro de 2003 e em fevereiro de 2004, o Ministério da Saúde (MS) da Venezuela patrocinou duas grandes oficinas em La Esmeralda, capital do município Alto Orinoco, estado do Amazonas, das quais participaram altos funcionários do Ministério e representantes dos povos indígenas de diferentes partes do Estado. Essas reuniões, presididas pelo, então, ministro da Saúde, Roger Capella, e organizadas pela recém-criada Coordinación Intercultural de Salud con Pueblos Indígenas (Cispi), foram uma concretização do princípio constitucional de democracia participativa, pelo qual se determina que o Estado e os representantes das comunidades devem estabelecer uma interação direta. A constituição também garante os direitos dos povos indígenas à participação política e a um serviço de saúde sensível à sua cultura. Naquele momento, esses eram mecanismos de desenho participativo das políticas de saúde pública para os povos indígenas completamente inéditos. Fazendo eco à linguagem utilizada na comemoração do quinto centenário da chegada dos europeus na América, os organizadores das oficinas deram o nome de Encuentros de Saberes (Encontros de Saberes).

O equilíbrio desses Encontros esteve, no entanto, fortemente inclinado para o conhecimento tradicional. De fato, essas foram iniciativas para promover e incorporar a medicina tradicional ao sistema de saúde. Os quatro alinhamentos principais que surgiram do segundo Encontro comprovam a ênfase dada aos elementos tradicionais: a criação de uma escola de xamãs; a incorporação de terapeutas tradicionais na folha de pagamento do MS; a criação de um "conselho estatal de saúde para os povos indígenas", um conselho assessor 
formado por terapeutas tradicionais e autoridades sanitárias regionais; e a recuperação do Programa de Medicina Simplificada, um programa que havia sido interrompido pouco antes e, que durante os últimos quarenta anos, havia capacitado os indígenas como enfermeiros de nível básico para oferecerem serviços de saúde em suas comunidades. $^{2}$

Consideremos por um momento a situação no Alto Orinoco, lugar onde se efetuaram os Encontros. Naquela época, estimava-se que $70 \%$ da população yanomami estava fora do alcance do sistema de saúde, ou seja, não recebia nenhum programa básico de saúde, tal como o Programa de Imunizações ou o Programa de Controle da Malária. Muitas comunidades yekuanas, segundo grupo indígena mais importante do município, também estavam fora do alcance do sistema ou recebiam uma atenção precária. A infraestrutura e a logística existentes nas áreas onde o sistema se fazia presente estavam extremamente deterioradas; a distribuição de medicamentos e de equipamentos médicos era mínima; a taxa de mortalidade infantil entre as comunidades yanomamis que recebiam atenção médica regular era dez vezes maior que a média nacional (Kelly, 2003).

Pensar-se-ia que a situação geral dos povos indígenas não estaria muito bem representada pelo caso particular dos yanomamis. No entanto, um conjunto de estudos sobre os problemas de saúde que afetam muitos outros grupos indígenas da Venezuela mostra que a desatenção ou subatenção às comunidades indígenas por parte do sistema de saúde é o panorama mais comum no resto do país (Freire e Tillett, 2007a). Além disso, outros grupos indígenas, como os pumés e os waraos, apresentam indicadores de saúde ainda piores que os yanomamis.

Examinando agora a distribuição dos sistemas médicos tradicionais, o panorama é diferente. O xamanismo yanomami apresenta um grande vigor. A maioria das comunidades tem um ou vários xamãs à sua disposição, e, pelo que sabemos, nunca se apresentaram problemas pela impossibilidade de acesso aos serviços de um xamã confiável, a menos que o paciente tenha sido levado a um centro de saúde distante. Igualmente, as práticas terapêuticas que incluem o 
xamanismo, a fitoterapia e os rituais coletivos são aspectos fundamentais da vida atual dos waraos e dos pumés (Barreto e Rivas, 2007; Wilbert e Ayala, 2007). Sem desconsiderar o fato de que as transformações históricas de diferentes aspectos da cultura afetaram de maneira evidente a forma e a força dos sistemas médicos tradicionais e, ainda, de que algumas comunidades indígenas podem estar legitimamente preocupadas por recuperar ou revitalizar diferentes aspectos de sua cultura, na ampla maioria dos casos o acesso rápido aos serviços médicos tradicionais é muito mais comum que aos serviços biomédicos. Desse modo, o acesso aos serviços de saúde biomédicos constitui, de longe, o principal problema de saúde para a maioria dos povos indígenas e o âmbito no qual podem ser mais eficazes as soluções de que dispõe o MS.

Em um contexto em que o acesso a serviços médicos tradicionais é muito mais fácil que aos serviços biomédicos, poderíamos perguntar-nos por que nos "Encontros" foi dada o que parece ser uma ênfase desproporcional aos sistemas médicos tradicionais, a ponto de excluir totalmente a discussão sobre a melhora e a expansão dos serviços biomédicos. Também devemos nos perguntar até que ponto as expectativas dos povos indígenas em relação ao sistema de saúde foram satisfeitas pelos encaminhamentos que surgiram nessas reuniões.

O presente trabalho tem duas partes, cada uma das quais utiliza uma dessas perguntas como ponto de partida. Em resposta à primeira pergunta, ponderarei algumas circunstâncias históricas e ideológicas que se combinam para propiciar um ambiente discursivo no qual podem surgir eventos como os Encontros, gerando as disparidades de enfoque que acabo de descrever. O que apresento é um comentário crítico sobre como certas premissas sobre "cultura" e "identidade" podem limitar nossa atenção quando se analisa o tema geral da saúde indígena. Essa visão restrita eclipsa as redes de relações - entre comunidade e Estado, entre índios e brancos - e, portanto, elimina suas implicações no perfil sanitário de uma comunidade qualquer. 
A segunda parte do ensaio continua vinculada ao tema da cultura e da identidade, mas com outro enfoque e iluminando outros problemas. Os Encontros, como diálogos interculturais, são instâncias de tradução e de interpretação mútua. Depois de apresentar um extrato das respostas dos yanomamis a uma das políticas apresentadas no segundo Encontro, irei me estender sobre o tema da tradução e os sentidos dados ao diálogo pelas duas partes para ilustrar os equívocos que, com tanta frequência, se apresentam nas relações entre o Estado e os índios. Essa análise toma suas referências das críticas internas que se dão no seio da antropologia em relação à interpretação das culturas, em particular aquelas expostas por Roy Wagner (1981) em The Invention of Culture. Falar em "equívocos" está longe de ser um capricho guiado pela economia teórica acadêmica ou a reformulação de antigas questões em termos novos e supostamente mais elegantes. Se o "equívoco controlado", de Viveiros de Castro (2004), se inspira em uma relação intelectual com a imaginação ameríndia, o "equívoco" não é parte menos essencial das relações intelectuais, afetivas e práticas entre índios e brancos: foi sem dúvida a característica mais relevante das relações que estudei no Alto Orinoco, na Venezuela, entre médicos e demais profissionais de saúde e os yanomamis que lá habitam.

Quero ressaltar que decidi enfatizar os Encontros porque nos convidam a refletir sobre a relação do Estado venezuelano com os indígenas. Desde a realização dos Encontros, apresentaram-se mudanças importantes no MS que fizeram com que as disparidades que aqui critico sejam, mais que a regra, uma exceção. No entanto, ainda quando o MS tenha provavelmente assumido a liderança em relação à formulação de políticas coerentes para os povos indígenas, talvez seja a exceção, entre todos os órgãos do Estado, em sua compreensão da "questão indígena". Portanto, os aspectos aqui descritos seguem sendo pertinentes em termos descritivos e analíticos. Esclareço também que o ensaio remete tanto à minha experiência de pesquisa quanto ao trabalho no MS e com os yanomamis, em um esforço continuado por vincular preocupações teóricas da antropologia com as problemáticas atuais dos yanomamis e daqueles que com eles trabalham. 
“Os Encontros de Saberes": equívocos entre índios e Estado em torno das políticas de ...

\section{Parte 1: Antecedentes históricos e condições ideológicas que precedem os Encontros}

O projeto de reconstrução da Nação, conhecido como Revolução Bolivariana, atraiu uma atenção e recursos consideráveis para os setores historicamente excluídos da sociedade. Com a Constituição de 1999, a Venezuela também se converteu em uma nação oficialmente multicultural e pluriétnica. A Constituição apresenta uma série de artigos que garantem o reconhecimento da cultura e da identidade indígena. Nessa nova circunstância histórica, os indígenas têm sido objeto de um grande número de programas sociais. A sensibilidade cultural também passou a ser parte integral da planificação das políticas públicas, assim como do debate político. No entanto, para além dos acontecimentos importantes que colocaram os povos indígenas em um lugar privilegiado nos programas e nas políticas do governo, deveríamos mencionar outras condições e motivações históricas e ideológicas que colaboraram com esse momento político para reforçar a centralidade da temática dos sistemas médicos tradicionais e da cultura indígena em geral.

Em primeiro lugar, a medicina tradicional tem sido sempre um dos símbolos diacríticos do movimento indígena. No campo da política da identidade que se forjou entre Estados e indígenas na América Latina, figuras como os xamãs e outros especialistas rituais se converteram em representantes proeminentes da luta dos povos indígenas pela conquista de direitos específicos. Esses foram peçaschave na estratégia geral de apropriação de valores e visões ocidentais sobre os índios, além de serem tradutores interculturais que proporcionam referências e orientação local no manejo das relações com a população dominante (ver Albert, 1993). ${ }^{3}$ Por outro lado, há um largo histórico de denúncias por parte do movimento indígena sobre os ataques de fundamentalistas religiosos às bases cosmológicas indígenas. $\mathrm{O}$ ataque direto e sistemático à vida ritual indígena dirigido pela Missão Novas Tribos entre várias populações (yanomami, piaroa, pumé, panare, yekuana, warao) e as acusações de etnocídio a que deu origem (Azpúrua, 1978; Lizot, 1976) constituem o melhor exemplo dessa situação na Venezuela. Se considerarmos ainda um con- 
texto histórico mais amplo de discriminação generalizada, é compreensível que o movimento indígena tenha procurado legitimar sua vida ritual em termos médicos e religiosos ao sancionar o reconhecimento dos sistemas religiosos e médicos em 1999, quando se elaborou a nova Constituição na Venezuela. ${ }^{4}$

A paridade de status com a biomedicina que implica esse reconhecimento, certamente, pode contribuir para contrapor o ataque, a discriminação ou o descrédito perante as terapias indígenas. De fato, como resultado imediato, as instituições do Estado venezuelano modificaram seu discurso oficial a respeito dessas terapias e submeteram à revisão suas leis, políticas e regulamentos. Voltando ao cenário particular dos Encontros, podemos entender que os encarregados de formular as políticas puderam sentir-se mais pressionados a enfrentar um tema desconhecido para eles, como a materialização do reconhecimento da medicina tradicional, que a dedicar esforços aos conhecidos problemas do sistema biomédico. O que desejo ressaltar é que há boas razões históricas para a busca de visibilidade da medicina tradicional, mas que essa trajetória histórica também contribuiu para favorecer a associação quase imediata entre os problemas de saúde dos índios e sua cultura.

Em segundo lugar, um número significativo de estudos médicos e antropológicos construiu suas perguntas de investigação de tal maneira que concentra sua atenção na cultura local e sua relação com a saúde. Esse é o caso que se apresenta sempre que uma característica cultural determinada aparece seja condicionando o perfil de uma doença em uma população determinada, seja limitando a eficácia de uma prática biomédica específica ou de uma intervenção em saúde pública. A variável independente da análise é a prática biomédica, e a cultura aparece, seja como um "fator de risco", seja como "barreira cultural para o acesso" ao sistema de saúde. Por sua vez, os estudos sobre a articulação dos sistemas biomédicos e tradicionais tendem a focalizar sua atenção nos graus de congruência e compatibilidade entre as teorias indígenas sobre as doenças, as práticas terapêuticas, as noções de pessoa e suas contrapartidas biomédicas. ${ }^{5}$ Essas orientações no campo da medicina e da antropologia médica 
“Os Encontros de Saberes”: equívocos entre índios e Estado em torno das políticas de ...

também têm privilegiado a análise da saúde indígena em termos culturais. Além disso, dentro dos temas culturais considerados há uma tendência a valorizar como tema central o campo "do médico" (etiologia, etnomedicina, conceitos de doença, corpo, saúde etc.).

Finalmente, deve-se ressaltar que os conceitos objetificados de cultura são os mais comumente difundidos entre os funcionários encarregados de formular as políticas. A cultura é concebida como uma lista de atributos: rituais, conhecimento especializado, cultura material etc. Como todas as coisas possuídas, a cultura está sujeita então a perdas, mas também a ser administrada. Tendo em vista que essa noção de cultura está intimamente relacionada com a "identidade", esta também pode ver-se erodida, fortalecida ou sancionada legalmente. Em resumo, um requisito básico para que eventos como os Encontros se deem nas condições que se deram é que a cultura e a identidade sejam objetificadas e concebidas como valores manejáveis.

$* * *$

Não há dúvidas de que a circulação e a sedimentação das ideias derivadas do conceito de cultura entre os diferentes atores - acadêmicos, indígenas, ativistas e empregados públicos - têm sido indispensáveis para reduzir o desequilíbrio de poderes entre o Estado e os povos indígenas em toda a América Latina. No entanto, na Venezuela, precisamente nesse momento de ação vigorosa que contrasta com um passado de abandono e de postergação da chamada questão indígena, parece pertinente essa reflexão conceitual, já que a aplicação de políticas inadequadas pode gerar tantos danos quanto as frágeis políticas do passado. Tanto a política de identidade indigenista como os discursos médicos e antropológicos têm favorecido a assimilação conceitual dos assuntos indígenas aos assuntos culturais e, em matéria de saúde, a assimilação dos assuntos culturais aos assuntos de âmbito médico. Esse duplo deslizamento analítico se vê acompanhado por um viés que reifica uma cultura como centro do problema, ao mesmo tempo que fragmenta redes complexas - como as que constituem um Ministério da Saúde - e suas relações constitutivas - como 
a relação entre índios e brancos. Esse é o contexto discursivo que pode fazer com que a disparidade entre a ênfase tradicionalista dos Encontros e os problemas de saúde indígena passe desapercebida.

\section{A reconexão da rede na saúde indígena}

Quero deter-me em duas consequências do que foi dito com vistas a delimitar alguns dos problemas que aparecem quando são postas em prática noções particulares de cultura e identidade, os quais foram ilustrados pelos Encontros. Deixo claro que esta não é uma crítica a respeito da exatidão ou não do conceito utilizado, mas sim das formas como o conceito se faz ou não útil no contexto de um MS dedicado à prestação, promoção e proteção da saúde. O primeiro ponto é ressaltar um aspecto - quiçá contraintuitivo, quando se examinam as transformações locais, produto da globalização - assinalado por Sahlins: "In the upshot, in any local sector of the global system the transformation assumes the dual appearance of assimilation and differentiation" (2000, p. 493).

É por isso que se faz necessária uma revisão analítica, pois

The struggle of non-Western peoples to create their own cultural versions of modernity undoes the received Western opposition of tradition versus change, custom versus rationality - and most notably its twentieth century version of tradition versus development (Sahlins, 2000, p. 514).

Por outro lado, na discussão sobre qual definição de cultura utilizar e como utilizá-la em um contexto abertamente político, no qual se busca algum tipo de reivindicação, devemos ser cautelosos e não obviar as relações de poder, ao que poderia nos levar a concepções exclusivamente simbólicas da cultura (Turner, 1993). Igualmente, devemos estar alerta diante da ilusão oposta de crer que a simples revelação das relações de poder é o fim - tanto no sentido da consumação como no de propósito - da análise (Sahlins, 1999). Ambos são exemplos de análises que operam a desconexão entre a cultura e seu contexto social, o que lembra um comentário formulado por M. Strathern:

Its ubiquity becomes a problem when culture ceases to work 
as a relational term... For as long as culture was understood as referring to local forms or expressions, it was thus contextualised by other descriptions of (social) relations between people. What is likely to disappear nowadays is that relational contextualisation (1995, p. 157, grifo do autor).

A falta de contextualização relacional é precisamente o que busco evocar para explicar a disparidade dos Encontros: um uso da "cultura" que se fecha em si mesma, desprovida de suas conexões, sejam aquelas próprias de seu contexto social ou próprias da rede que vincula diversos contextos sociais (interétnicos). Permita-me continuar com esse segundo ponto.

\section{Alguns efeitos da fragmentação analítica das redes e de uma concepção não relacional de cultura}

A distribuição desigual de responsabilidades

Briggs (2003) dá um exemplo contundente dos perigos de considerarmos a cultura como a causa principal dos problemas de saúde de um povo. Ele mostra como a tomada de decisões no manejo da epidemia de cólera entre os waraos do Delta do Orinoco (1992-1993) baseou-se consideravelmente na imagem que se tinha da cultura indígena. A cultura warao foi invocada para culpar os próprios waraos da epidemia, explicando a predisposição natural dos waraos para serem portadores de cólera e valendo-se de uma lista de aspectos desabonadores que limitavam sua resposta ao tratamento e às intervenções terapêuticas. Essa distribuição de culpas baseada na cultura, além de estigmatizar os waraos, encobria assim a gestão irresponsável do Estado no manejo da crise. O ponto a ressaltar com esse caso, além da mortal irresponsabilidade do Estado, são as razões pelas quais ela pode passar inadvertida. Algo similar com a disparidade a qual me referi em relação aos Encontros que também passou desapercebida.

O fato de se dar ênfase excessiva à cultura, interpretada como um conjunto de crenças, como a base sobre a qual as pessoas reagem à doença, pode inverter gravemente a distribuição de responsabilidade entre o paciente e o provedor de serviços. Diante dessa limi- 
tação, o enfoque na economia política da saúde se apresenta como o melhor remédio, pois ilumina o encadeamento de causalidade nos perfis locais de saúde e distribui as responsabilidades de tais perfis ao longo de uma cadeia de atores e instituições.

\section{Cultura indígena, outras culturas}

Ao examinarmos o enfoque geral das análises da saúde indígena, encontramos uma variante do problema recém-exposto: a quantidade de trabalhos realizados sobre a cultura e a saúde dos povos indígenas não tem um contrapeso equivalente nos trabalhos antropológicos sobre a cultura do Estado e sua burocracia e como limitam a eficácia de um sistema de saúde. Posto de forma simples, as adaptações para fazer com que um serviço seja mais sensível à cultura estão mais ao alcance que as intervenções sobre a "cultura administrativa" do Estado. Uma intervenção na burocracia do Estado seria, sem lugar a dúvidas, a adaptação de maior transcendência em relação ao impacto na saúde indígena. Com frequência se escuta que os indígenas morrem vítimas de doenças prevenidas e facilmente tratáveis. Sem dúvida, essas afirmações são persuasivas para lutas pela saúde dos grupos indígenas, mas representam uma má interpretação da realidade, já que uma "simples" pílula na selva, ou mesmo uma vacina em um hospital citadino, não diz respeito apenas ao remédio em si, mas também a um sistema de saúde cheio de regulamentações, oficinas, assinaturas, empregados, protestos, medicamentos e motores de popa. Como bem expressa Latour, as linhas aéreas são as que voam, não os aviões. A saúde dos indígenas melhora pelas mesmas razões que melhora a saúde dos habitantes de Caracas, e isso exige uma maior distribuição dos esforços analíticos de antropólogos da saúde ao largo da rede que une as comunidades aos ministérios.

\section{A necessidade de ir mais além do "médico"}

Se a adoção de um enfoque centrado na economia política de saúde é uma das estratégias para reconectar o cultural e o social, também é apropriado olharmos na direção oposta, até a cosmopolítica da comunidade. Ao concentrar-se nos aspectos médicos, a maioria 
dos estudos antropológicos descarta o peso das relações políticas interétnicas que se desenvolvem no funcionamento dos sistemas de saúde nas comunidades indígenas. O sistema de saúde participa, agora desde uma perspectiva indígena, de uma economia simbólica da alteridade (Viveiros de Castro, 1996) que constrói relações e significados sociais tão influentes como os explicitados por uma economia política da saúde. Resulta abundantemente claro que entre os yanomamis o status de "estrangeiros" e "inimigos potenciais" dos brancos tem repercussões no caráter e na eficiência do sistema de saúde que superam, de longe, as consequências derivadas das incompatibilidades no conhecimento e da prática médica entre os yanomamis e os profissionais de saúde brancos. Se limitarmos a análise das articulações dos sistemas médicos ao campo do "médico", estaremos distorcendo gravemente as experiências sobre o sistema de saúde em que se encontram tanto os médicos quanto os yanomamis. Tendo em vista que a sociabilidade yanomami é comparável a de outros grupos indígenas na Amazônia, suspeito que esse aspecto político da articulação dos sistemas de saúde não tem sido analisado com toda profundidade que requer, diferentemente do que ocorre com análises que partem do "global".

Agora examinemos o primeiro ponto, a necessidade de desfazermos a oposição convencional entre tradição e mudança em favor de uma visão que inclua a primeira como um marco da segunda, e assim podemos entender melhor como as pessoas mudam de maneira tradicional ou têm a tradição de mudar (Sahlins, 1993).

\section{Desfazendo a oposição tradição-mudança}

Os enigmas morais da mudança cultural

É frequente encontrar, entre profissionais envolvidos com políticas públicas para índios, uma dificuldade de pensar a mudança cultural. Ainda que não universal, é comum um esquema conceitual 
que opõe uma bondade rousseauniana dos indígenas e os males essenciais do Ocidente: o capitalismo, o individualismo, o materialismo e a destruição ambiental. Daí a postura que vê todas as mudanças que ocorrem entre os povos indígenas como uma perda cultural provocada pela força devastadora do Estado, do capitalismo ou do sistema mundial. Isso se contrapõe ao desejo comum das pessoas de indigenizar a modernidade (Sahlins, 1993), de controlá-la e de colocála a serviço de suas próprias ideias sobre o que significa uma vida que valha a pena viver.

No campo da saúde indígena esse dilema sustenta uma preocupação comum compartilhada por médicos e antropólogos, segundo a qual os sistemas médicos indígenas são vulneráveis e se desmoronam ante os sistemas biomédicos (Buchillet, 1991b). A evidência disponível mostra, antes, que, quando os dois sistemas entram em contato, os indígenas os colocam em uma relação - conceitual e prática - de complementaridade mais que de competição (Buchillet, 1991b). A suposição segundo a qual a biomedicina é uma força em si mesma capaz de colapsar a cultura das pessoas é um falso problema, pois se radica na ideia de que a biomedicina tem uma eficácia tão óbvia que é suficiente para fazer com que as pessoas abandonem "suas crenças" - que com tanta frequência as qualificam de "sabedoria milenar". O resultado é duplamente paternalista: termina-se desvalorizando um sistema que, pela fragilidade sancionada, deve ser protegido. Um exemplo desse tipo de contradição insolúvel: ao falar sobre os pumés das savanas de Apure e dos planos para a ampliação do sistema de saúde integral que é muito requerido pelas comunidades, Barreto e Rivas comentam: “Los conocimentos y prácticas terapéuticas, entre las que ocupa un lugar central la ceremonia del tõhê, se verán inevitablemente vulnerados ante la introducción de la medicina occidental" (2007, p. 278).

Daí segue que o sistema de saúde que será posto em marcha deve tomar uma série de medidas para "combater esta ameaça" (Barreto e Rivas, 2007). Os autores estão muito conscientes da necessidade dos serviços biomédicos e de nenhuma maneira argumentam contra. No entanto, é contraditório emitir esse veredicto em um 
artigo que descreve como - apesar da história extraordinariamente sombria dos deslocamentos forçados, do racismo e das correrias de índios que os pumés sofreram até nossos dias - eles mantêm muitas características do que se pode qualificar como um sistema médico tradicional. Ainda assim, seu conhecimento parece vulnerável diante da medicina ocidental.

\section{Multiculturalismo e a preocupação moderna com a identidade}

Taylor (1994) afirma que o multiculturalismo anda junto com a identidade individual e coletiva pela simples razão de que a compreensão do que as pessoas têm de si mesmas entra em diálogo com a compreensão do que os outros têm sobre o que somos. O autor também nos lembra de que, para que tenham surgido o multiculturalismo e a política de identidade, uma conceitualização e uma preocupação com a identidade pessoal e a consciência de si mesmo tiveram primeiro que ser convertidas em senso comum, de maneira que as reivindicações baseadas nessas razões foram percebidas como sensatas. Segundo a tese de Taylor, essa preocupação moderna pela identidade somente pode ser produzida uma vez que: a) se dissolveram ou debilitaram as hierarquias sociais fixas e a política exclusivista da honra que mantinha as elites e valorava de uma forma diferente os cidadãos, sendo substituída por uma política universalista da dignidade humana; e b) se desenvolveu um sentido de identidade individualizada, um conceito "que chega com um ideal, aquele de ser verdadeiro comigo mesmo e meu jeito particular de ser [...] Falarei nisto como o ideal de 'autenticidade"' (p. 28).

O ideal de autenticidade, por sua vez,

greatly increases the importance of self-contact by introducing the principle of originality: each of our voices has something unique to say. Not only should I not mold my life to the demands of external conformity; I can't even find the model by which to live outside myself. I can only find it within (Taylor, 1994, p. 30).

O ponto pertinente em nossa discussão é que a preocupação moderna pela identidade é historicamente contingente: todos po- 
dem ter ideias mutáveis e contextuais sobre a identidade pessoal e coletiva, mas é errado supor que a humanidade compartilha o caráter e o grau de interesse da nossa preocupação moderna pela identidade. E é esse ideal de autenticidade, ao qual está vinculada nossa ideia de identidade, que entra em conflito com a dissolução da oposição tradição-mudança, a qual Sahlins considera um fator necessário para a compreensão da indigenização da modernidade.

Quero examinar agora um dos principais textos programáticos que orientavam a política do MS no momento em que se realizaram os Encontros, com o objetivo de ilustrar as tendências que acabamos de descrever. Em sua caracterização dos povos indígenas e de seus problemas de saúde, faziam-se poucas referências à heterogeneidade cultural e histórica dos diferentes povos indígenas da Venezuela, sem falar da heterogeneidade no interior da cada povo. Uma visão geral das "sociedades em transição", que não era inexata em si mesma, dava por certa a existência de problemas de "sobrevivência cultural" e "alienação" entre todos os povos indígenas.

Esse documento também se baseava em um entendimento holístico biopsicossocial da saúde no lugar da noção mais simples de "ausência de doenças" e do enfoque individualizado e organicista da biomedicina convencional. A nova conceitualização da saúde na qual se baseava esse programa de ação estipulava:

La salud es la capacidad y el derecho de cada persona a elegir aquellas posibilidades de vida que le permiten ser cada vez más dueña de si misma, menos alienada de si. La salud como epifenómeno de vida es un proceso integral y armónico de autoposesión, de autoreconocimiento, autorespeto, autovalorización y conlleva al reconocimiento, respeto y valoración del otro en toda su diversidad biológica y cultural (Venezuela, 2004, p. 24).

As visões amplas da saúde são muito bem-vindas. No entanto, a proeminência que essa definição de saúde dá à identidade e sua semelhança com o 'ideal de autenticidade' deve fazer-nos perguntar o quanto ela pode ser útil se aplicada acriticamente a povos que podem não compartilhar essa nossa preocupação com a identidade. É precisamente esse tipo de questão que abordaremos na segunda parte deste ensaio. 
“Os Encontros de Saberes”: equívocos entre índios e Estado em torno das políticas de ...

\section{Parte 2}

Nesta segunda parte, procuro mostrar o potencial analítico do conceito de "equívoco controlado" de Viveiros de Castro (2004) para o estudo das relações entre índios e brancos ou índios e Estado.

\section{Uma conversa bizarra}

Começo meu relato no momento em que o representante do Ministério da Saúde (doravante simplesmente MS) explica que uma das atribuições do Consejo Indígena de Salud é alertar as autoridades regionais de saúde sobre as deficiências do sistema de atendimento. O MS, então, quis saber que outras atribuições os yanomamis consideravam pertinentes para esse novo Conselho. O MS teve que repetir a indagação três vezes aos anciãos yanomamis ali reunidos. Estes, por sua parte, estavam pensando em sua própria mensagem para os representantes do Estado.

O representante yanomami respondeu: ${ }^{6}$

[...] Vocês apenas levam nossas opiniões e não fazem nada, apenas as lêem, é o único que fazem. Vocês [napes, "brancos"] nunca nos dizem "será feito como vocês dizem" [...] Infelizmente eles [napes] nos mesquinham os remédios, o que realmente queremos são médicos com conhecimento, vivendo conosco. É assim que estou pensando $[\ldots]$.

Outro yanomami:

Vocês só nos fazem cansar de falar [...] Nós, os yanomamis, não conhecemos os remédios [...] nem praticamos medicina natural [...] só nos tratamos com algumas plantas e assim, somente pouco a pouco, nos recuperamos, somente às vezes nos recuperamos com plantas, e é por isso que vocês deveriam ajudar aos anciãos, dando remédios aos jovens [representantes bilíngues] [...] Nós os yanomamis não conhecemos nada dos remédios [...] com os alucinógenos potentes podemos matar os espíritos das doenças epidêmicas, mas essa shawara não morre, somente às vezes nos recuperamos, por isso, o único bom que vocês podem fazer é ajudar-nos. Vocês somente se aproveitam do nome

\section{ILHA}

volume 11 - número 2 
dos yanomamis, não acabem com o dinheiro que obtêm com nosso nome! Ajudem-nos! [...] Os yanomamis morrem porque nós não sabemos sobre os remédios [...].

Vocês [napes] pensam que nós podemos nos curar facilmente com os espíritos hekuras. São somente algumas vezes que os hekuras nos curam, eles de fato matam os espíritos da doença, mas em outros casos não podem nos curar. Os hekuras seguem as pegadas [dos espíritos agressores], seguem seu rastro, não se equivocam, eles seguem o rastro e logo nos recuperamos [...].

Eu estou cansado de tudo isto, somente se vocês nos ajudam terá valido a pena $[\ldots]$ vocês nos cansam.

O MS pergunta: "O que vocês pensam que esses representantes [do Conselho Indígena de Saúde] deveriam fazer? Que atribuições vocês lhes dariam?".

O tradutor yanomami (jovem bilíngue) fala aos anciãos: "Sobre esses dois representantes que estamos elegendo, o que vocês pensam sobre eles, como vamos vigiá-los? [...]".

Nesse momento, um velho começa a responder algo sem relação à pergunta e os jovens, impacientes, empeçam a indicar a ele o que ele deveria dizer. O velho repete as sugestões ao pé da letra, e o tradutor passa a mensagem ao MS.

O tradutor yanomami fala ao MS:

Se nossos representantes estão atentos, eles têm que reclamar para que as coisas melhorem e vocês [napes] devem ser sinceros com eles para que eles possam trazer a informação [suponho que das reuniões do Conselho Indígena] [...] Desta maneira penso que isso pode funcionar bem.

O MS responde:

Que pensam que esse Conselho deveria fazer, além de reclamar, deveria fazer algo mais? Como esse comitê nos vai ajudar? Porque as coisas não são só deste lado [o sistema de saúde não é só responsabilidade das autoridades] [...] Perguntem ao xamã o que ele pensa.

Outro yanomami fala: 
[...] Eu pedi remédios faz muito tempo, a primeira vez [em uma reunião acontecida três anos antes] [...] O único que quero é que vocês cheguem com remédios. Meu filho já traduziu isso para vocês faz muito tempo [novamente na reunião acontecida há três anos]. Nós xamãs matamos os espíritos da doença, se ao mesmo tempo vocês, os médicos, nos ajudam com seus remédios, então trabalharemos juntos. Isso foi o que eu disse há muito tempo.

Como podemos apreender desses extratos, mesmo não compreendendo completamente a proposta do Conselho Indígena de Saúde, a postura dos anciãos yanomamis perante o enfoque tradicionalista do Encontro é clara: “queremos remédios, médicos gradua$\operatorname{dos}[\ldots]^{\prime \prime}$.

\section{Traduções de brancos e de yanomamis}

Para além do que poderíamos criticar as propostas do segundo Encontro - a descontextualização de uma escola de xamãs, os problemas com o assalariamento e o estabelecimento de critérios para definir médicos tradicionais 'legítimos' etc. -, ele nos oferece um cenário curioso: brancos oferecendo medicina indígena (indígena aos olhos do Estado) e índios pedindo remédios de brancos (brancos aos olhos yanomamis). Ainda que pareçam estranhos, os mal-entendidos que subjazem a esse evento intercultural são muito comuns e, de fato, são parte fundamental das relações entre brancos e yanomamis. A análise que segue se aproxima da proposta de Wagner (1981), pois o que ocorre, segundo o autor, na relação entre o antropólogo e seus sujeitos (nativos) deve também ser intrínseco à antropologia que executa o Estado em seu esforço por implementar o paradigma multicultural.

Em um evento como esse Encontro, os yanomamis e o Estado estão tentando se entender. Esse entendimento procede da extensão do convencional para incorporar algo que aparece como novo ou externo - a biomedicina de um lado, os sistemas médicos tradicionais de outro. Essa extensão criativa acarreta a necessária redução dos sentidos/significados (meanings) dos outros aos termos de nos- 
sos símbolos. Exploremos em seguida os pressupostos subjacentes que afetam as traduções que os yanomamis e os brancos fazem uns dos outros, pressupostos cujas essências se evidenciam nesse Encontro.

Os representantes do Estado assemelham a figura do xamã à do médico, por meio da função de cura que ambos cumprem. Dessa maneira, o conceito conhecido de 'médico' se estende para incorporar a figura, menos conhecida, de 'xamã'. O mesmo princípio opera no interesse geral que o Estado teve, durante esse Encontro, em relação à medicina tradicional: um interesse guiado pela valorização euro-americana da cultura, entendida - grosso modo - como a acumulação de feitos e técnicas, de coisas que se produzem (Wagner, 1981). A inevitável redução implicada em cada extensão interpretativa fica evidente se, tomando o caso do xamã, consideramos outras ressimbolizações possíveis. Em um contexto mais religioso, pode-se assemelhar o xamã à figura de um padre católico ou de um pastor protestante (ver Hugh-Jones, 1994). Em um contexto político, o xamã pode ser assemelhado antes a um embaixador ou até mesmo a um espião. E, se ainda não vemos as autoridades do Ministério da Defesa buscando aproveitar o potencial militar e de inteligência dos xamãs, é porque o Estado multicultural privilegia certas ressimbolizações ao mesmo tempo que torna outras impensáveis. Mas é importante ver que a operação que faz de um xamã um médico é idêntica àquela que o converte em embaixador ou espião. ${ }^{7}$

Os representantes yanomamis, por sua vez, solicitam médicos, tecnologia, medicamentos industrializados e conhecimentos biomédicos. Para além do reconhecimento do impacto positivo da biomedicina, esse interesse é expressão de um interesse mais geral em nosso 'cargo', que, por sua vez, estende a valorização pelos yanomamis das relações humanas em nível interpessoal e coletivo. Como exemplo desse pressuposto cultural, podemos recordar dos objetos solicitados aos brancos, muitas vezes, com veemência. Uma vez obtidos, no lugar de serem acumulados, são postos em circulação, fortalecendo ou multiplicando relações com efeitos políticos diversos. Os médicos brancos e outros representantes do Estado tendem a interpretar a incessante demanda de bens dos yanomamis em 
“Os Encontros de Saberes”: equívocos entre índios e Estado em torno das políticas de ...

termos materialistas e pensam que aos yanomamis apenas interessam os brancos pelas coisas que levam. Certa vez eu indaguei a um yanomami de forma provocativa: "Vocês só gostam dos brancos por nossas coisas!". "Não", me respondeu, "as coisas não são assim, Jose, se não gostássemos dos brancos, de onde tiraríamos as coisas?!" (paráfrase). Essa resposta é crucial pois aponta a relevância da relação que se faz visível no ato de obter os objetos dos brancos, maior que a importância dos objetos em si. De fato, os bens em circulação replicam essa relação branco-yanomami muito mais além da interface inicial. O intercâmbio de bens manufaturados entre os yanomamis diferencia os que dão dos que recebem, os primeiros incorporando significados de 'branco' e os segundos de 'yanomami', em um novo contexto de relações ao qual me referirei mais adiante.

Pois bem, essa orientação convencional está vinculada a outras duas. A primeira é uma preocupação pela diferenciação pessoal e coletiva que é a expressão de uma tendência generalizada entre os ameríndios a 'virar outro' antes de 'ser eu', assim como apontou Viveiros de Castro (1992). As cosmologias amazônicas postulam uma comunidade essencial entre humanos e não humanos ao estender o estatuto de pessoa a estes últimos. Assim sendo, torna-se necessária a diferenciação individual e coletiva constante contra um fundo de similitude baseado na continuidade da alma e da cultura através da descontinuidade transespecífica (Viveiros de Castro, 1998). A diferenciação em nível da divisão entre humanos e não humanos obriga que sejam feitos esforços para se diferenciarem corpos humanos de corpos animais (Gow, 1997; Vilaça, 2005). No interior das coletividades humanas, são constantes os esforços para se distinguirem parentes por oposição aos afins - basta recordarmos o caráter de cismogênese de muitos rituais de reprodução social (ver Albert, 1985; Fausto, 2000; McCallum, 2001; Vilaça, 2006). No domínio mítico, como demonstrou Lévi-Strauss (1991), a incompatibilidade da identidade completa com a vida social se reflete por todas as Américas na impossibilidade da identidade absoluta entre gêmeos, cuja diferenciação constante gera um 'desequilíbrio perpétuo', tanto descritivo como prescritivo, da socialidade. 
No contexto do Encontro, um tipo de diferenciação que podemos chamar de 'virar branco' é particularmente relevante. Através do intercâmbio histórico dos yanomamis do Alto Orinoco com diferentes agentes do Estado (missionários, sistema de saúde etc.), eles adquiriram um habitus e conhecimentos brancos. Um novo contexto de significados e práticas lhes provê oportunidades de diferenciação contra seus compatriotas yanomamis de rio acima, com menos contato com a 'sociedade nacional', e contra os índios e os brancos que vivem rio abaixo, mais 'civilizados' que eles. O uso de roupas, a posse e possibilidade de prover objetos manufaturados, a habilidade de falar espanhol e mediar as relações com os brancos, a participação na política indígena e de partidos, tudo isso sustenta um contexto significativo a serviço da diferenciação que possibilita. Esse contexto nasce da extensão criativa do espaço sociopolítico convencional definido pela gradação de aliança e alteridade entre comunidades yanomamis (Albert, 1985). Esse espaço sociopolítico convencional classifica, a partir de qualquer comunidade, todas as demais em corresidentes, amigos ou aliados, e inimigos.

Grosso modo, as relações com cada esfera social vão da reciprocidade generalizada, passando pela equilibrada e chegando à negativa, conforme o esquema clássico definido por Sahlins (1972). Os intercâmbios recíprocos, reais e simbólicos, vão dos bens e de mulheres entre corresidentes e aliados, até a troca de doentes e mortos entre grupos inimigos. No novo contexto, no entanto, a alteridade não se define em função da inimizade, mas em termos do 'devir histórico em branco', ou seja, da gradação de transformação em napë (Y. Napë é o inimigo potencial/branco). O termo napë ilustra a expansão de contexto de que falamos. Originalmente se refere aos inimigos e à animosidade, e atualmente é o termo de referência aos brancos e às práticas associadas a eles. Ser 'yanomami' e ser 'napë' adquire um novo sentido contextual, e é assim que os yanomamis do Orinoco podem falar com orgulho em ser 'civilizados', indicando um tipo de dupla identidade yanomami/napë sem contradição. Quero esclarecer, no entanto, que, na prática, tal dualidade não se trata 
“Os Encontros de Saberes”: equívocos entre índios e Estado em torno das políticas de ...

de uma 'identidade': todo seu sentido radica nas duas maneiras de diferenciar-se que estão ao alcance dos yanomamis do Orinoco, possibilitadas pelas relações com os yanomamis de rio acima - mais índios ou menos transformados que eles - e com os índios e os brancos de rio abaixo.

A segunda orientação convencional tem a ver com a produção de pessoas. Visto desde a perspectiva da economia política de pessoas, ela se refere ao controle da distribuição de produtores (homens) mais que de recursos (Rivière, 1984). Intimamente ligado à necessidade de diferenciação, o parentesco pressupõe sua construção de pessoas através da corresidência e da comensalidade. Os yanomamis podem se referir ao bem-estar de sua comunidade, assinalando seu tamanho ou a quantidade de crianças. Suspeito que o fazem porque esse é um bom augúrio, tanto por assegurar a provisão de produtores e matrimônios como por assegurar uma boa posição na política intercomunitária.

É de vital importância ter em mente que a maneira díspar como o sistema de saúde é distribuído entre os yanomamis - com seus postos de saúde, seus medicamentos, seus médicos brancos e yanomamis treinados como enfermeiros - tem contribuído historicamente tanto para a diferenciação como para a produção de pessoas da qual estamos falando. Os yanomamis que falam no Encontro o fazem a partir dessa experiência. Sem dúvida nenhuma há uma preocupação pela saúde, tanto nos que sentem o dever de atender os que foram historicamente excluídos do sistema de saúde (autoridades de saúde, médicos etc.) como entre aqueles que suportam a dor de conviver com altas taxas de mortalidade (yanomamis). No entanto, por mais brutal que seja a exclusão social dos yanomamis, reduzir suas motivações para buscar serviços biomédicos de saúde ao tamanho dessa exclusão estaria tão longe de exprimir a importância e o significado do potencial de diferenciação do sistema de saúde para eles, assim como de explicar a preocupação das autoridades sanitárias com a cultura e a identidade. Além disso, obviaria por completo os equívocos que caracterizam a relação entre brancos e índios. 


\section{Equívocos}

A discussão de Viveiros de Castro (2004) sobre esses equívocos é particularmente útil para analisar essa situação em que os yanomamis e o Estado estariam se traduzindo mutuamente. O conceito de 'equívoco' aparece em uma reflexão do autor sobre o que a antropologia pode aprender do perspectivismo ameríndio como método. Em um mundo perspectivista as espécies (humanos, espíritos, animais) compartem uma cultura comum, mas habitam naturezas diferentes/diversas. Daí segue que a comunicação transespecífica seja sempre uma tradução. A tradução tem por objeto manter a consciência de que existem diferentes referentes sob cada representação. Ela deve recordar que o mundo de coisas e eventos é, na realidade, um mundo de homônimos e ações, que não podemos perder de vista que aquilo que os humanos veem, por exemplo, como sangue os jaguares veem como cauim - para utilizar um exemplo do próprio Viveiros de Castro - e que, por trás de um acidente como uma picada de cobra, pode haver um agente, tipicamente, um xamã inimigo.

Viveiros de Castro (2004) chama 'equívoco controlado' a proclividade ameríndia de ter consciência da existência de distintos sistemas de referência aos quais cada coisa e evento podem se referir. Nesse sentido positivo, como método, o perspectivismo pode subverter o método antropológico clássico baseado na premissa da existência de uma natureza única e comum, e de culturas múltiplas e particulares. Mas Viveiros de Castro também utiliza o termo 'equívoco' para se referir precisamente à falta de consciência dos antropólogos da existência dos equívocos que estão tão implicados na tradução intercultural como, para os ameríndios, na comunicação transespecífica. Apesar de o autor não o fazer, poderíamos chamar esse tipo de falta de consciência dos equívocos de 'equívoco não controlado' e que, nesse sentido mais negativo, se referiria às traduções literais, à extensão de simbolizações, sem se deixar afetar pelos significados da cultura do outro. Assim, portanto, no primeiro caso controlado -, seja no antropólogo, seja no nativo, existe uma consci-

ência da existência de homônimos, de referentes diversos por trás de uma representação comum; e, no segundo caso, seja no antropólo- 
go ou no nativo, o que há é uma falta de consciência da homonímia, e se pressupõe a univocalidade, ou seja, está pressuposta a existência de um sistema de referência único e compartilhado ao qual todas as representações se referem.

Seguindo Viveiros de Castro (2004), utilizo o termo 'equívoco' em sua acepção não controlada para descrever a circunstância do Encontro. O termo é mais apropriado que um 'mal-entendido', que suporia uma confusão de significados compartilhados, e não o desconhecimento da significação alternativa com a qual nos confrontamos no Encontro.

\section{Equívocos tomados por mal-entendidos}

No Encontro, ambas as partes, Estado e yanomami, têm um interesse comum na 'saúde'. Os pressupostos do Estado, no entanto, infundem em seu entendimento de 'saúde' sua consternação com a cultura e a identidade. Eles estão literalmente em busca de 'fazer índios', crendo firmemente que esse é um caminho para fazer dos índios pessoas saudáveis. Para os yanomamis, 'saúde', nesse contexto, não pode se referir senão ao sistema biomédico de saúde; eles não têm nenhum problema com a identidade nem com suas terapias tradicionais, e veem claramente 'a saúde' como parte intrínseca do 'devir branco'. ${ }^{8}$ A situação tem uma semelhança notável com outro 'encontro', um a que Lévi-Strauss (2006) se refere, relacionado às investigações que espanhóis e indígenas realizavam uns sobre os outros - uma anedota recuperada por Viveiros de Castro tanto para descrever o perspectivismo ameríndio (1998) como para falar sobre os equívocos interculturais (2004). A anedota relata que, enquanto os espanhóis discorriam sobre a posse ou não da alma dos indígenas - a posse de um corpo lhes era óbvia -, os indígenas observavam os cadáveres dos espanhóis capturados para ver se os corpos se decompunham - a posse de uma alma não estava em questão.

Quero ressaltar que o encontro dos projetos divergentes de 'fazer índios' e 'devir branco' em torno do problema da 'saúde' não é simplesmente um assunto de mal-entendidos, de haver caminhos 
diferentes para resolver o mesmo problema. O problema é precisamente que não é o mesmo problema. Estamos perante um equívoco: a falta de consciência de significados alternativos, a reconfiguração dos símbolos de outros nos termos de nossas convenções. No caso que nos ocupa: os diferentes sentidos de 'branco' e 'índio' entendidos desde a perspectiva de brancos e índios. Os yanomamis não estão se transformando nos brancos que os brancos concebem, nem os yanomamis se veem como os índios que o Estado quer reinstaurar (Viveiros de Castro, 2006). Na história de Lévi-Strauss (2006) nos confrontamos com os diferentes significados de 'corpo' e 'alma', nas perspectivas espanhola e indígena. Em ambas as situações, 'saúde' e 'humanidade' funcionam como homônimos entre dois sistemas de referência distintos, mas o fenômeno da equivocação não controlada opera contra a percepção de outro sistema de referência, a equivocação esconde sua existência e faz com que a homonímia oscile entre percepções de 'entendimento' e 'mal-entendido', sempre dentro do sistema de referência do ator em questão.

Desse espelhamento, que Wagner demonstrou perseguir a antropologia, resulta descartar a função mediadora de conceitos como 'cultura' e 'identidade'. Esses conceitos metaforizam nossas relações com os indígenas, e essas metáforas têm sua contraparte na relação dos indígenas conosco. Como disse Wagner em sua discussão sobre a relação entre o antropólogo e os melanésios: “The fact that 'cargo' and 'culture' metaphorize the same inter-societal relation, while doing so in opposite directions, so to speak, makes them effectively metaphorizations of each other [...]" (1981, p. 32).

Alargando a fronteira de nosso problema para mais além da situação do Encontro, quero propor que, da mesma maneira que 'cultura' e 'cargo' são metáforas uma da outra, o processo de 'become indian' (Jackson, 1991) que induz o Estado - na realidade, o processo de 'fazer índios' que inclui o desenvolvimento da etnicidade, a popularização de visões objetificadas de 'cultura', a juridificação do conceito de território etc. - pode ser visto como a contrapartida metafórica do 'virar branco'. A equivalência entre esses dois processos somente é visível se incluirmos na tradução os diferentes entendi- 
mentos de 'branco' e 'índio' que têm esses atores e assim substituirmos os significados que o Estado confere à 'identidade' e à produção de coisas que chamamos 'cultura' por aqueles significados que os yanomamis conferem à diferenciação e à produção de pessoas. Ainda que pareça contraintuitivo, o 'fazer índios do Estado' e o 'devir branco dos índios', como 'cargo' e 'cultura', "metaforizam a mesma relação intersocial, enquanto o fazem em direções opostas".

Assim, uma vez que o interesse comum em 'saúde' já não pode dissimular a divergência entre os projetos do Estado e dos yanomamis, de 'fazer índios' e 'devir branco', a homonímia cede, certa tensão cresce e assume a forma de uma resistência mútua ao projeto de cada um: os brancos tendem a interpretar o 'devir branco' dos yanomamis como uma 'alienação' e 'perda cultural'; os yanomamis, por sua conta, criticam os brancos por sua mesquinhez dos serviços biomédicos e sua falta de confiabilidade. A sensação de um 'diálogo de surdos' começa a prevalecer, as pessoas sentem que não estão se comunicando, mas o duplo equívoco se mantém soterrado, tomado por um 'mal-entendido' que poderia ser solucionado pela via da interação (voltam a perguntar ao xamã o que ele pensa do Conselho Indígena de Saúde...). Se tudo falha, um termina por duvidar das capacidades mentais do outro - lembremos que, na gíria popular do estado do Amazonas (Venezuela), aos brancos chamam 'racionales' em contraposição aos índios.

\section{Equívocos tomados por entendimentos}

Pois bem, se essa fosse a única relação possível entre brancos e yanomamis, alguém poderia perguntar-se como pode dar-se algum tipo de relação construtiva entre o Estado e os yanomamis. Na obra The Domestication of the Savage Mind, Goody (1977, p. 8) se coloca a mesma pergunta para criticar Lévi-Strauss na sua caracterização dos 'modos de pensamento' entre os nativos (bricoleur) e os modernos (engenheiro), propostos em La Pensée Sauvage. De acordo com Goody, se, como sugere Lévi-Strauss, nós e eles abordamos o mundo físico a partir de lados opostos, como que ele (Goody) nunca percebera o 
'hiato comunicativo' que se esperaria ao relacionar-se com outra cultura? Poderíamos discutir se Goody exagera na diferença proposta por Lévi-Strauss, sobre se é maior, menor ou se, na realidade, não existe. Esse exercício, suspeito, seria absolutamente fútil. Caso reconhecermos, novamente seguindo a pista de Wagner (1981), a cultura como criação inventiva de significados através da extensão de nossos símbolos convencionais, então a situação de 'choque cultural', que para o antropólogo recém-chegado ao campo cristaliza 'a cultu-

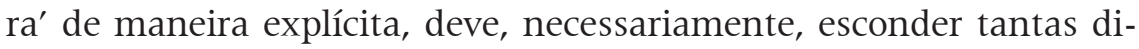
ferenças entre antropólogo e nativo com as quais evidencia. Portanto, para responder à pergunta de Goody de uma maneira diferente à sua própria, essa possibilidade de comunicação está ao menos facilitada por uma situação provavelmente muito mais comum de homonímia na qual o avanço do projeto de cada parte no encontro intercultural possibilita que o fenômeno do equívoco passe não mais por 'mal-entendido', mas, pelo contrário, por 'entendimento'. Essa situação começa por uma afinidade de interesse em algo que joga um papel relevante no projeto de cada um. À medida que esses projetos avançam, a homonímia persiste sob o disfarce do 'entendimento'.

O melhor exemplo dessa situação é o interesse comum na 'civilização' que encontramos na relação histórica entre os agentes do Estado e os yanomamis do Orinoco, assim como em outras partes da Amazônia histórica e contemporânea. No meu modo de ver, podemos distinguir, no lado do Estado, duas facetas do processo de 'civilização'. Por um lado, está o projeto de inculcar um estilo de vida ocidental e cristão que bem pode chamar-se 'fazer brancos'. Aqui estou pensando no enfoque no corpo indígena para transformar seu habitus: o uso de roupas, o ensinamento da higiene, a promoção da moradia unifamiliar, e assim por diante. A avalanche de bens manufaturados que entrou nas comunidades do Orinoco nessa época inicial de missionarização tinha, entre outros, o objetivo de preparar os yanomamis para a melhor compreensão da mensagem cristã, um tipo de persuasão do corpo para melhor convencer a alma. Os yanomamis, por sua parte, também estavam interessados nesse tipo de 'civilização', pois convergiam com o processo de 'devir branco' 
“Os Encontros de Saberes”: equívocos entre índios e Estado em torno das políticas de ...

que vínhamos discutindo: a aquisição de 'corpos brancos' entendida no sentido perspectivista como a captação de capacidades e afecções (Viveiros de Castro, 1998) e das novas possibilidades de diferenciação entre 'ser branco' e 'ser yanomami' que começavam a perfilarse. Portanto, o interesse comum na 'civilização' fazia com que o projeto de 'fazer brancos' dos missionários fosse homônimo ao 'devir branco' dos yanomamis. À medida que cada projeto avançava, os equívocos passavam por 'entendimento'.

Mas há uma segunda faceta desse projeto de 'civilização' que dura até nossos dias e é integral à operação do sistema de saúde e, com efeito, inerente a qualquer incorporação à estrutura do Estado que poderíamos chamar de 'fazer a sociedade'. Fazer a sociedade se refere ao conjunto de esforços propiciatórios das condições para o relacionamento frutífero com as comunidades yanomamis, em um contexto social que, para a maioria dos missionários, médicos e brancos em geral, lhes parece descomunalmente caótico. Os brancos se veem forçados a criar líderes com quem negociar, a instaurar rotinas e esquemas próprios à educação formal, a estabelecer horários de trabalho nos postos de saúde, regras de acesso aos recursos desses postos (em particular ao uso dos motores e barcos), a organizar o território e o pessoal yanomami em termos de otimização logística e administrativa. As reuniões para definir os acordos com as comunidades se multiplicam. Resumindo, os brancos dedicam um enorme esforço coletivizante para instaurar as regras de convivência que permitem uma 'vida em sociedade' com os yanomamis.

'Fazer a sociedade' é menos convergente com o projeto yanomami de 'devir branco'. Em primeira instância porque o primeiro é um processo coletivizante - uma instauração de convenções - e o segundo é um processo particularizante - que desfaz convenções. Em segundo lugar, porque os esforços de instalar uma sociedade que fazem os brancos não se aplicam a um vazio social. Não faz falta recordar que há uma organização sociopolítica yanomami, mas sua ordem convencional raras vezes é reconhecida pelos brancos, que costumam ver apenas anarquia, ausência de sociedade. Em terceiro lugar, porque o 'fazer sociedade' faz confrontar a promoção, 
pelos agentes do Estado, de um modo de domínio político separado da sociedade com o rechaço radical por parte dos yanomamis de formas de controle social separadas da sociedade (Clastres, 1977). Nessas circunstâncias, a gerência desse novo socius branco-yanomami é, no mínimo, turbulenta.

Assim, da mesma maneira que no Encontro de Saberes, uma sensação de mal-entendido prevalece, e os brancos e os yanomamis parecem resistir às intenções uns dos outros.

\section{Etnopolítica e reconhecimento indígena dos equívocos}

Todos os representantes do Estado promovem algum tipo de 'civilização' entre os yanomamis. As relações entre os yanomamis e cada uma dessas categorias de brancos oscilam entre entendimento e mal-entendidos homonímicos, dependendo do grau de êxito dos projetos de cada um. Os brancos, leia-se, missionários, ativistas, antropólogos, médicos etc., nesse contexto, devem acomodar suas expectativas às visíveis limitações de seu projeto, motivados seja por convicções religiosas, seja por um sentido de dever, ou não levar as coisas tão a sério - é sempre a opção mais proveitosa. Eles também podem frustrar-se e ir, porque sempre podem. Os yanomamis do Orinoco, por sua vez, também ajustam suas expectativas. Ao fim e ao cabo, o acesso a um sistema de saúde e a presença de missionários são suficientemente convergentes com seu 'devir branco'.

Vale a pena indagar se em algum momento os equívocos são reconhecidos por algumas dessas partes, se a coincidência de significação alternativa pode escapar à ilusão de ter graus de significados compartilhados. Suspeito que o terreno da etnopolítica seja o mais fértil para engendrar essa consciência. Mais ainda, dado que são os indígenas os que por décadas veem acumulando a experiência de lidar com um universo de representantes do Estado, parece muito mais provável que seja a antropologia indígena dos brancos a que tenha reconhecido traços de significação alternativa. Os representantes estatais sempre mudam, e seu conhecimento sobre os índios raras vezes supera o estado da insipiência. O Estado vem desempe- 
nhando um papel fundamental na criação da etnopolítica, mas os únicos etnopolíticos são os índios. E é através do exemplo do discurso de Davi Kopenawa, assim como o descreveu Bruce Albert (1993), que podemos ver com maior clareza o reconhecimento de um sistema alternativo de significação.

Albert escreve sobre as sutilezas do discurso político de Davi no contexto da defesa da terra yanomami diante das sucessivas ondas de garimpeiros que invadiram seu território nas últimas décadas. Esse discurso é uma sofisticada antropologia dos brancos, antropologia tanto dos garimpeiros como dos ambientalistas, inimigos e aliados dos yanomamis, respectivamente. Albert esclarece que essa não é uma mera repetição de um discurso aprendido e atraente para os brancos ambientalistas. Davi se baseia na mitologia e no pensamento xamânico, conhecimentos que proveem a matriz interpretativa sobre os brancos e que, por sua vez, se reconfiguram para dar conta das realidades em mudança. Davi compartilha a preocupação pela floresta tropical e pela natureza com o movimento ambientalista, uma aliança sustentada pela homonímia entre os conceitos de 'natureza', 'ambiente' e 'ecologia' e o conceito yanomami de urihi. Está consciente, no entanto, das diferenças radicais nas premissas que subjazem a esse par de conceitos.

As preocupações conservacionistas dos ambientalistas pressupõem uma relação sujeito-objeto com a natureza, a qual a faz gerenciável para o proveito humano. Os yanomamis, pelo contrário, mantêm uma relação social com aquilo que nós englobamos sob a categoria de natureza, que para eles está povoada de seres espirituais em interdependência com os seres humanos. São relações constitutivas da sociedade, relações que não podem sobreviver ao consumo predatório de recursos naturais que é sustentado por um conceito objetificado de natureza. Davi estabelece um contraste crítico entre essa preocupação com as relações sociais e o conhecimento xamânico e a obsessão dos brancos pela produção e pelo consumo de objetos e pelo conhecimento associado a eles (a escrita e a escola). Em sua justa medida, o discurso de Davi se equivale a uma "crítica xamânica da economia política da natureza" - como Albert titula o 
seu artigo -; uma crítica, poderíamos acrescentar, que transcende o terreno epistemológico e manifesta uma consciência de equívocos entre dois regimes ontológicos diferentes.

\section{Para concluir: do 'fazer índios' ao 'fazer gente saudável'}

Os Encontros de Saberes nos deram a oportunidade de refletir sobre nossos conceitos de cultura e identidade em contextos de aplicação nas políticas públicas de saúde indígena. A partir da primeira parte do ensaio, destacamos a necessidade de dissolver, no nível analítico, a oposição tradição-mudança de maneira que nossos conceitos e ferramentas de análise sejam consonantes com a realidade que pretendemos descrever. Por outra parte, ficou claro que o conceito de cultura deve voltar a seu contexto relacional, tanto aquele que se encontra dentro da sociabilidade indígena como aquele que se dá nas redes que conectam as comunidades com os diferentes níveis do aparato do Estado. Isso deve ter como resultado uma distribuição mais adequada das responsabilidades ou causalidades entre os atores institucionais e comunitários; entre os determinantes médicos e políticos da saúde; entre as culturas do Estado e dos índios; entre a economia política global e a sociocosmopolítica dos indígenas.

Na segunda parte vimos concretamente os equívocos que resultam da extensão irreflexiva de nossos conceitos de identidade e cultura. Os problemas aqui esboçados não podem ser encarados com a busca de novos conceitos. Nossa discussão deixa claro que o problema não se radica nos conceitos, e sim no estatuto que lhes damos. Volto a Wagner (1981, p. 30-31, grifo do autor) sobre esse ponto:

We must be able to experience our subject matter directly, as alternative meaning, rather than indirectly, through literalization or reduction to the terms of our ideologies. The issue can phrased in practical, philosophical, or ethical language, but in any case it devolves upon the question of what we want to mean by the word "culture", and how we choose to resolve, and to invent, its ambiguities.

Enquanto o Estado continuar implementando sua política multicultural, obviando o papel mediador das noções de cultura e 
“Os Encontros de Saberes”: equívocos entre índios e Estado em torno das políticas de ...

identidade, estará forçado a reduzir o xamã à figura de um médico. E daí em diante não há como parar as traduções literais, pois, visto como um médico, seu papel deve ser institucionalizado, transformado em uma profissão, a qual, por sua vez, requer uma regulamentação (o registro dos xamãs 'legítimos'), a compensação salarial e a produção sistemática de profissionais (a escola de xamãs). Tal é a força dessa transliteralização que, no segundo Encontro de Saberes, o ministro da Saúde da época explicou para a audiência como, com o salário, o xamã poderia, a partir de então, dedicar todo o seu tempo à cura de pacientes, sem ter que se preocupar com as atividades mais mundanas da vida, como a caça e o cultivo, ou seja, as coisas que fazem de uma pessoa um homem ou uma mulher. Manifestando a angústia do estilo de vida urbano, esse juízo se baseia em uma divisão entre 'trabalho' e 'vida doméstica' que, sendo fundamental na vida dos modernos, é bastante alheia às concepções yanomamis do que eles "fazem na vida".

Já que se trata de escolher, devemos reter o caráter mediador da noção de cultura. Somente assim poderemos perceber que 'devir branco' não é uma perda cultural, mas uma maneira muito indígena de mudar, e que 'fazer índios' não é um ganho cultural, mas uma aspiração própria dos modernos. Se 'cultura' e 'identidade' deixam de ser o objeto da preocupação fundamental para um ministério como o da Saúde, estaremos preparados para transladarmos um pouco da seriedade com que tratamos esses termos para as pessoas e o que dizem. Um programa de ação intercultural que considera as pessoas com seriedade reconhece que muitas vezes 'cultura' codifica uma série de ideias sobre o que os índios consideram fundamental para uma vida que valha a pena ser vivida. No caso dos ameríndios e do Estado, uma preocupação primordial com o território, por exemplo. Dito de outra maneira, o reconhecimento da existência de sistemas alternativos de significação deveria guiar as políticas públicas interculturais para a criação das condições em que se produzem os significados alternativos. E isso nos leva de novo a terra, à saúde e, fundamentalmente, à discussão a respeito das maneiras pelas quais é possível reduzir a assimetria de poder entre Estado e indígenas. Que- 
ro enfatizar que não se trata de avaliar se os indígenas ganham ou perdem cultura, mas sim de estabelecer critérios para distinguir as políticas públicas boas das ruins, pois se, como sugere Wagner (1981), a antropologia literal termina sendo má antropologia, menos ainda podemos esperar das políticas públicas, que, conscientemente ou não, são uma antropologia aplicada.

\section{Notas}

${ }^{1}$ Tradução de Beatriz Matos.

${ }^{2}$ A revitalização desse programa se distinguiu das outras três propostas por não estar particularmente relacionada à medicina tradicional.

${ }^{3}$ Para se ter uma visão das vantagens e das desvantagens da incorporação de interpretações ocidentais pelos indígenas na política de identidade na Amazônia, ver, entre outros, Jackson (1991, 1995a, 1995b) e Conklin (1997).

${ }^{4}$ Ver Constituición de la República Bolivariana de Venezuela, artigos 120 a 122.

${ }^{5}$ Ver, por exemplo, os volumes de Santos e Coimbra (1994), Buchillet (1991a), Chiappino e Alès (1997), Freire e Tillett (2007a, 2007b). Há notáveis exceções que ressaltam o peso das relações interétnicas no funcionamento de um sistema de saúde, como Garnello (2003) e Briggs (2003).

${ }^{6}$ Todas as falas dos yanomamis foram transcritas e traduzidas do yanomami por mim junto com um colaborador yanomami.

${ }^{7}$ Aliás, A-C Taylor (1981, p. 648) reporta que os xamãs mais reputados entre os achuar e quíchua da Amazônia equatoriana são pessoas que têm passado pelo exército nacional e que "parte de seus poderes sobrenaturais parecem estar vinculados com seu status de [soldados] e a sua associação com o exército", o que mostra que ressimbolizações impensáveis para o Estado não escapam à imaginação indígena.

${ }^{8}$ Sempre que os yanomamis utilizam o termo 'saúde', em espanhol, é para se referir ao sistema de saúde biomédico, seus medicamentos, médicos, práticas e doenças vinculadas aos brancos.

\section{Referências}

ALBERT, Bruce. 1985. Temps du sang, temps de cendres: représentation de la maladie, système rituel et espace politique chez les Yanomami du sud-est (Amazonie brésilienne). Tesis (Doctoral) - Université de Paris X, Paris, 1985. . L'Or cannibal et la chute du ciel. L'homme, v. 126/128, p. 349-378, 1993.

AZPURUA, Carlos. Yo hablo a Caracas. Documental. Departamento de Cine de la Universidad de los Andes, 1978.

BARRETO, Daisy; RIVAS, Pedro. Los Pumé. In: TILLETT, German; TILLETT, Aime (Eds.). Salud indígena en Venezuela: volumen II. Caracas: Ministerio de Salud, 2007. p. 247-330.

\section{ILHA}

volume 11 - número 2 
“Os Encontros de Saberes”: equívocos entre índios e Estado em torno das políticas de ...

BRIGGS, Charles. Stories in the Time of Cholera: Racial Profiling During a Medical Nightmare. Los Angeles: University of California Press, 2003.

BUCHILLET, Dominique. Medicinas tradicionais e medicina occidental na Amazônia. Belém: Edições Cejup, 1991a.

. A antropologia da doença e os sistemas oficiais de saúde. In:

BUCHILLET, Dominique (Ed.). Medicinas tradicionais e medicina occidental na Amazônia. Belém: Edições Cejup, 1991b.

CHIAPPINO, Jean; ALÈS, Caterine (Eds.). Del microscopio a la maraca. Caracas: Editorial Ex Libris, 1997.

CLASTRES, Pierre. Society Against the State. Trans. by R. Hurley. Oxford: Basil Blakwell, 1977.

CONKLIN, Beth. Body Paint, Feathers, and vcrs: Aesthetics and Authenticity in Amazonian Activism. American Ethnologist, v. 24, p. 71 1-737, 1997.

FAUSTO, Carlos. Of Enemies and Pets: Warfare and Shamanism in Amazônia. American Ethnologist, v. 26, p. 933-956, 2000.

FREIRE, German; TILLETT, Aime. Salud indígena en Venezuela: volumen I. Caracas: Ministerio de Salud, 2007a. $\overline{2007 \mathrm{~b} .}$

. Salud indígena en Venezuela: volumen II. Caracas: Ministerio de Salud,

GARNELLO, Luiza. Poder, hierarquia e reciprocidade: saúde e harmonia entre os Baniwa do Alto Rio Negro. Rio de Janeiro: Fiocruz, 2003. (Coleção Saúde dos Povos Indígenas).

GOODY, Jack. The Domestication of the Savage Mind. Cambridge: Cambridge University Press, 1977.

GOW, Peter. O parentesco como consciência humana: o caso dos Piro. Mana, v. 3, n. 2, p. 39-65, 1997.

HUGH-JONES, Stephen. Shamans, Profets, Priests and Pastors. In: THOMAS, Nicholas; HUMPHREY, Caroline (Eds.). Shamanism History $\theta$ the State. Ann Arbor: University of Michigan Press, 1994. p. 32-75.

KELLY, Jose Antonio. 2003. Relations within the Health System among the Yanomami in the Upper Orinoco. Tesis (Doctoral) - University of Cambridge, Venezuela, 2003.

2005.

. Notas para uma teoria do "virar branco". Mana, v. 11, n. 1, p. 201-234,

JACKSON, Jean. Being and Becoming an Indian in the Vaupés. In: URBAN, Greg; SHERZER, Joel (Eds.). Nation-States and Indians in Latin America. Austin: University of Texas Press, 1991.p. 131-155.

\section{ILHA}


. Culture, Genuine and Spurious: The Politics of Indianness in the

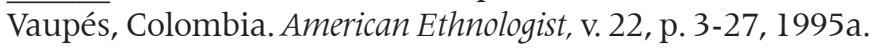

. Preserving Indian Culture: Shaman Schools and Ethno-Education in the Vaupés, Colombia. Cultural Anthropology, v. 10, p. 302-329, 1995b. LÉVI-STRAUSS, Claude. Histoire de Lynx. Paris: Plon, 1991. . Race et Histoire. Paris: Denoël, 2006. (Collection Folio/Essais). LIZOT, Jaques. The Yanomami in the Face of Ethnocide. Copenhagen: IWGIA, 1976. (IWGIA documents 22).

McCALLUM, Cecilia. Gender and Sociality in Amazonia: How Real People are Made. Oxford: Berg, 2001.

RAMOS, Alcida. Indigenism: Ethnic Politics in Brazil. Madison: University of Wisconsin Press, 1998.

RIVIÈRE, Peter. Individual and Society in Guiana: A Comparative Study of Amerindian Social Organization. Cambridge: Cambridge University Press, 1984. (Cambridge Studies in Social Anthropology 51).

SAHLINS, Marshall. Stone Age Economics. New York: Aldine, 1972.

. Goodbye to Tristes Tropes: Ethnography in the Context of Modern World History. The Journal of Modern History, v. 65, n. 1, p. 1-25, 1993.

. Two or Three Things I know about Culture. Journal of the Royal Anthropological Institute, v. 5, n. 3, p. 399-421, 1999.

. Culture in Practice: Selected Essays. New York: Zone books, 2000.

SANTOS, Ricardo; COIMBRA Jr., Carlos (Eds. ). Saúde e povos indígenas. Rio de Janeiro: Fiocruz, 1994.

STRATHERN, Marilyn. The Nice Thing about Culture is that Everyone has it. In:___ (Ed.). Shifiting Contexts: Transformations in Anthropological Knowledge. London: Routledge, 1995. p. 153-176.

TAYLOR, Anne-Christine. God-Wealth: The Achuar and the Missions. In: WHITTEN Jr., Norman (Ed.). Cultural Transformations and Ethnicity in Modern Ecuador. Urbana, Chicago, London: University of Illinois Press, 1981. p. 647676.

TAYLOR, Charles. The Politics of Recognition. In: . Multiculturalism: Examining the Politics of Recognition. Princeton: Princeton University Press, 1994. p. 25-74.

TURNER, Terrence. From Cosmology to Ideology: Resistance, Adaptation and Social Consciousness among the Kayapo. In: ASSOCIAÇÃO BRASILEIRA DE ANTROPOLOGIA, 1987, Belém do Pará.

\section{ILHA}


“Os Encontros de Saberes”: equívocos entre índios e Estado em torno das políticas de ...

. Anthropology and Multiculturalism: What is Anthropology that Multiculturalists should be Mindful of it? Cultural Anthropology, v. 8, n. 4, p. 411-429, 1993.

VENEZUELA. Constitución de la República Bolivariana de Venezuela. Venezuela, 1999.

. MSDS. Programa Intercultural de Salud con los Pueblos y Comunidades Indígenas de Venezuela. Venezuela, 2004.

VILAÇA, Aparecida. Chronically Unstable Bodies: Reflexions on Amazonian Corporalities. Journal of the Royal Anthropological Institute, v. 1 1, p. 445- 464, 2005. UFRJ, 2006.

. Quem somos nós: os Wari' encontram os brancos. Rio de Janeiro: Ed.

VILLALÓN, Maria Eugenia. Los E'ñapa. In: FREIRE, German; TILLETT, Aime (Eds.). Salud indígena en Venezuela: volumen II. Caracas: Ministerio de Salud, 2007. p. 13-74.

VIVEIROS DE CASTRO, Eduardo. From the Enemy's Point of View: Humanity and Divinity in an Amazonian Society. Chicago: University of Chigaco Press, 1992.

. Images of Nature and Society in Amazonian Ethnology. Annual Review of Anthropology, v. 25, p. 179-200, 1996.

. Cosmological Deixis and Amerindian Perspectivism. Journal of the Royal Anthropological Institute, v. 4, p. 469-488, 1998.

. GUT Feelings about Amazonia: Potential Affinity. In: WHITEHEAD, Rival e Niel (Eds.). Beyond the Visible and the Material: The Amerinidianization of Society in the Work of Peter Rivière. L. Oxford: Oxford University Press, 2001.p. 19-43.

. O nativo relativo. Mana, v. 8, p. 113-148, 2002.

. Perspectival Anthropology and the Method of Controlled Equivocation. Tipiti, v. 2, n. 1, p. 3-22, 2004.

. No Brasil, todo mundo é índio, exceto quem não é. In: . Povos indígenas no Brasil 2001-2006. São Paulo: Instituto Socioambiental, 2006.

WAGNER, Roy. The Invention of Culture. Chicago: The University of Chicago Press, 1981.

WILBERT, Werner; AYALA, Cecilia. Los Warao. In: FREIRE, German; TILLETT, Aime (Eds.). Salud indígena en Venezuela: volumen II. Caracas: Ministerio de Salud, 2007. p. 331-396. 
Jose Antonio Kelly Luciani

ZENT, Standford. Donde no hay médico: las consecuencias culturales y demográficas de la distribución desigual de los servicios médicos modernos entre los Piaroa. Antropológica, v. 79, p. 41-84, 1993.

Recebido em: 16/19/2010

Aceite em: 28/10/2010 